\title{
Structural Equation Model Analysis of Urban Public Service Satisfaction
}

\author{
Lulu Li ${ }^{1, a} \quad$ Xiangdong Cai ${ }^{1, b, *}$ \\ 1 Jilin University of Finance and Economics, School of Public Administration, Changchun, China \\ a719229899@qq.com, byzx8170561@163.com \\ ${ }^{*}$ Corresponding author
}

Key words: Urban public service, Public satisfaction, Structural Equation Modeling.

\begin{abstract}
In order to improve the efficiency of urban public services and scientifically evaluate the status of urban public service satisfaction, we use Structural Equation Modeling and American Customer Satisfaction Index (ASCI) to analyze urban public service satisfaction. According to the characteristics of the urban public services, structural model and observational model were established. In this paper, we make an empirical study of public services satisfaction by using the survey data in Changchun city and put forwards the proposals for the public services satisfaction.
\end{abstract}

\section{Introduction}

The urban public service satisfaction is the degree of comparison with the public's actual feeling and its expectation. The theory of satisfaction, first, Professor Fornell from National Quality Research Center(NQRC) in Michigan University Business School, created the Swedish Customer Satisfaction Barometer (SCSB) in 1989 ${ }^{[1]}$. Then, Fornell developed and established the Fanair Mode based on the SCSB, namely Customer Satisfaction Index (CSI) ${ }^{[2]}$, other countries combined theory and practice had revised this model to suit their own countries. With the rise of public management movement, more and more developed countries in Europe and US have introduced CSI to government performance evaluation. Sweden Customer Satisfaction Barometer and National Customer Satisfaction Index have been widely used in evaluation of public service satisfaction with government agencies. At present, the reference to public service satisfaction research is quite limited in domestic, Liu $\mathrm{Wu}$ et al. (2006) ${ }^{[3]}$ has established the customer satisfaction index system and model of government public service, and analyzes the practical feasibility of investigation and measurement. Yang Fenghua (2008) ${ }^{[4]}$ has used the structural equation model to evaluate the public satisfaction of public sector and pointed out some questions that should be pay attention to evaluate public satisfaction. Zhang Huiping (2011) ${ }^{[5]}$ has made a demonstrable study of public service satisfaction of Yin Chuan City by using cross analysis and correlation analysis methods, and put forwards some suggestions on it. Ji Jiangming (2013) ${ }^{[6]}$ has evaluated the public service satisfaction index of 34 cities by using entropy TOPSIS method.

In conclusion, the domestic researches of urban public service satisfaction are most concentrated on the evaluation of specific industries or departments, but there are few studies on the evaluation of urban public service satisfaction. In terms of the analytical method, unilabiate analysis or linear regression analysis is used to analysis a single index, and correlation coefficient cannot reflect the causal relationship between index and overall satisfaction. Binary analysis such as cross analysis and correlation analysis is used to evaluate the relationship between two variables, but it can only provide a direct effect rather than a possible in direct effect. There is some research on public satisfaction of public sector with structural equation model but no further verification analysis was conducted using questionnaire data. This paper with the questionnaire data from Changchun city, constructed the structure and measurement model of urban public service based on ASCI and combined with the improvement of urban public service characteristics, then structural equation model and AMOS 21 were used to analyze the urban public service satisfaction in Changchun. 


\section{Structural Equation Modeling}

Structural Equation Modeling (SEM) is a multivariate statistical analysis technique which combines factor analysis and path analysis. SEM can turn the variables into latent variables which cannot be observed directly and needs to be studied. These latent variables are reflected by some variables which can be observed, thus establishing the structural relationships between them. SEM is a kind of comprehensive statistical analysis method which can replace multiple regression, factor analysis, covariance analysis and so on. Since the 1980s, SEM has developed rapidly, making up statistics methods and becoming an important tool of statistical analysis.

\subsection{Basic Form of SEM}

SEM includes measurement model, structural model and model assumption. It's the most general case of structure model which the endogenous and exogenous variables in causal model are both latent variables, every potential exogenous and endogenous variable have measurement model, the model is as follows:

(1) Structural Model

The relationship between latent variables can be expressed as follows:

$$
\eta=B \eta+\Gamma \zeta+\zeta
$$

In this model, $\eta$ is endogenous latent variable, $\zeta$ is exogenous latent variable, $B$ is internal latent variable coefficient matrix which describes the relations among $\eta, \Gamma$ is exogenous latent variable coefficient matrix which describes the effect of $\zeta$ on $\eta, \zeta$ is the residual of SEM that reflects the unexplained parts of $\eta$ in the equation.

(2) Measurement Model

The relations between indicators and latent variables can be written into the measurement equation as follows:

$$
Y=\Lambda_{y} \eta+\varepsilon \quad X=\Lambda_{x} \xi+\delta
$$

$Y$ is the observed variable of endogenous variable $\eta, \Lambda_{y}$ is the coefficient matrix between $Y$ and $\eta$,it's composed of the factor load matrix of $Y$ in $\eta, \varepsilon$ is the measurement error of $Y . X$ is the observed variable of exogenous latent variable of $\xi . \Lambda_{X}$ is the coefficient matrix between $X$ and $\xi$, it's composed of the factor load matrix of $X$ in $\xi, \delta$ is the measurement error of $X$.

\section{Urban Public Service Satisfaction Structure Equation Model}

\subsection{American Customer Satisfaction Index Model}

This paper is the improvement of the famous American customer satisfaction index model (ASCI). ASCI is a macroscopic evaluation index to evaluate the quality of economic output, it's based on the process of consumption and service to evaluate customer satisfaction index. ASCI includes the national overall satisfaction index, department satisfaction index, industry satisfaction index and enterprise satisfaction index, it's one of the most complete and best applied system model of national customer satisfaction theory model. ACSI model structure is shown in Fig.1.

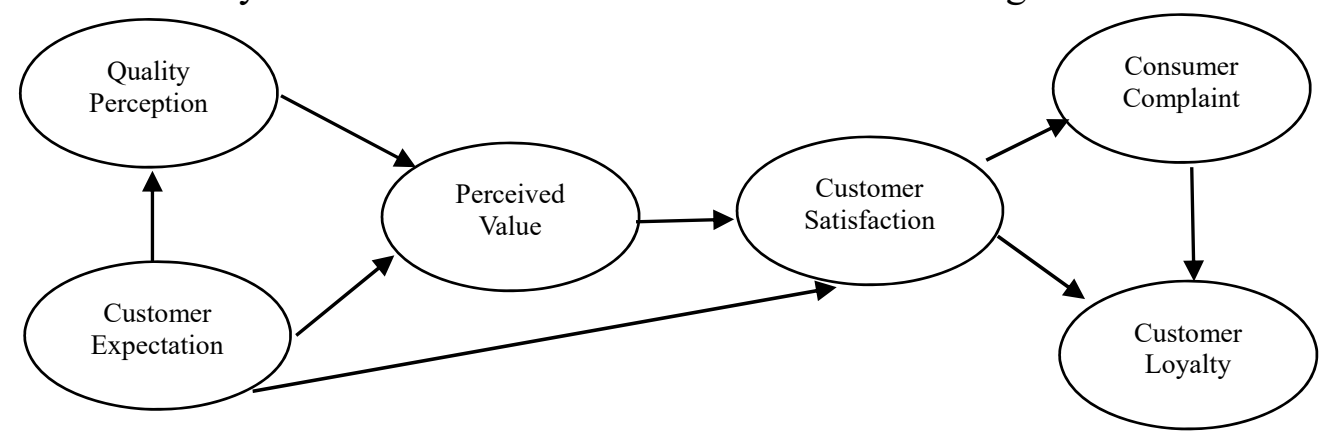

Fig. 1. ACSI Model 


\subsection{Construction of Urban Public Service Satisfaction Model}

ACSI is a system used to evaluate and improve organization performance which is based on customer. It is widely used in private sector and mainly used in specific industries or enterprises in China. The research on social management mainly focuses on teaching, library and other service organizations, but the research on the evaluation of public satisfaction are limited. There have differences between public sector service and private sector service, which concrete expression to differences on service principals, service categorizations, prices and service competition ${ }^{[7]}$. Therefore, when constructing the urban public service satisfaction model, the service differences between public sector and private sector should be taken into account, it also should improve the ACSI model with the characteristics of urban public service. This paper has eliminated the latent variables "Perceived Value", because the private sector service aims of the benefits. These services are compatible with tangible or invisible products and with low fees. Public sector service is not profit-driven, the price is guided by the market and the service is monopolized by the government with no competition, and it provide independent and invisible service. But there is competition among businesses that offer business services. In addition, the satisfaction of public service has influenced the evaluation of the city image, thus, replacing "customer loyalty" with "city image".

The model we build includes five factors (latent variables): quality perception, public expectation, public satisfaction, public complaint and city image. The first two factors are the leading influence variables, the latter two factors are the subsequent effect variables, and the five latent variables interacted and constrain each other. The structure paths are shown as below:

$\begin{aligned} & \text { Structure Path Design Diagram } \\ & \text { Perception }\end{aligned} \mid \begin{aligned} & \text { Basic Path Hypothesis } \\ & \text { public expectations have path } \\ & \text { influence on quality perception } \\ & \text { public perceived have path } \\ & \text { influence on public satisfaction } \\ & \text { public satisfaction have path } \\ & \text { influence on public complaint } \\ & \text { public satisfaction have path } \\ & \text { influence on city image } \\ & \text { public complaint have path } \\ & \text { Expectation }\end{aligned}$

Fig. 2. Structure Path of Changchun Urban Public Service Satisfaction

\subsection{The Choice of Measurable Variables}

Since the potential variables in the conceptual model cannot be measured directly, the multidimensional observation variables should be constructed, that is to establish the index system to estimate the variables.

When choosing latent variables "Public Expectation" we select the "public overall expectation on urban public service"," public expected reliability on urban public service" and "practical engineering expectations", these three variables are selected based on the ACSI and practical situation of Changchun.

The content of urban public service, the book "New Theory on Urban Administration in China" has formed an integrated frame, it includes urban infrastructure service, the comprehensive consideration for enterprises, and comprehensive service to residents (the popularization of urban culture and science, education services), service for urban disadvantaged and the resist service of urban public disaster. So, when choosing the measurable factors of latent variables "Quality Perception", we considered comprehensively and selected three measurable variables as follows: public culture service, urban public safety feeling and compulsory education quality feeling.

Public satisfaction is a concept that is based on public and public perception. The public satisfaction is a ratio which depends on the public acceptance of a product or service and the experience before accepting it. The higher the ratio, the higher the satisfaction is. Reference to the choice of measurable variables satisfaction index, we selected three measurable variables: the overall 
satisfaction of government and related departments works, the gap with the expected service and the satisfaction of urban public service efficiency.

We selected three measurable factors: public opinion, public comment times to relevant departments and public complain to measure the latent variable "Public Complaint", the choice is referenced to the case of "the behavior and willingness of residents" medical consumption analysis" in a book, named "Structural Equation Models: Methods and Applications" which was compiled by Yi Danhui ${ }^{[8]}$, a statistics expert in China.

The interpersonal harmony can reflect the situation of urban civilization and the public satisfaction of urban service. The growing environment of minors has a great influence on the physical and mental health of minors, and the healthy growth of minors will also benefit the construction of urban public service. City appearance and environment can reflect "City Image" directly, according to the actual situation of Changchun we selected "minors' growth environment", "the degree of interpersonal harmony" and "city appearance and environment" to measure latent variable "City Image". The indicator system table as follows:

Table 1. Index System of Changchun Urban Public Service Satisfaction

\begin{tabular}{|c|c|c|}
\hline & Latent variables & Measurable Variables \\
\hline 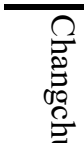 & Public Expectation & $\begin{array}{l}\text { Overall Expectation } \\
\text { Public expectations of reliability } \\
\text { Expectations of project }\end{array}$ \\
\hline$\underset{\Xi}{\Xi}$ & Quality Perception & $\begin{array}{l}\text { Public cultural service } \\
\text { Urban public safety } \\
\text { Compulsory education quality }\end{array}$ \\
\hline 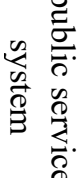 & Public Satisfaction & $\begin{array}{l}\text { Satisfaction with the work of municipal government and } \\
\text { related departments } \\
\text { Satisfaction of urban public service efficiency } \\
\text { The gap with the expected service }\end{array}$ \\
\hline 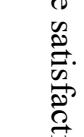 & Public Complaint & $\begin{array}{l}\text { Public opinion } \\
\text { Public comment times to relevant departments } \\
\text { Public complain }\end{array}$ \\
\hline : & City Image & $\begin{array}{l}\text { The growing environment of minors } \\
\text { The degree of interpersonal harmony } \\
\text { City appearance and environment }\end{array}$ \\
\hline
\end{tabular}

\section{The Empirical Study on Urban Public Service Satisfaction in Changchun}

\subsection{Data Source}

The quantitative analysis survey data come from 5 main urban areas and 4 development zones (excluding Shuangyang district) in Changchun, a total of 600 households in 30 communities were surveyed for 22 industries service quality evaluation. We use field survey, questionnaire survey and telephone survey methods to collect the assessment data objective, real and reasonable. The questionnaire survey adopts cluster sampling and random systematic sampling to choose the subject. Telephone surveys are used to confirm the respondents. The field visit adopts the form of investigate in secret and perspicacious. In this research, there were 1000 questionnaires distributed and a total of 902 of valid samples were collected with answering rate $90.2 \%$. The questionnaire includes: basic information of the individual, service quality evaluation of government, service quality evaluation of industry and evaluation of city image. Through this survey, we investigate the urban public service satisfaction of Changchun in different urban areas with different gender, age and background.

\subsection{Reliability and Validity of Data}

This questionnaire adopts the index of internal consistency to measure the reliability of the data. At present the Cronbach's $\alpha$ used widely to examine dependability of the data. The method is: calculate Cronbach's $\alpha$ coefficient, it indicates the reliability of index is acceptable when $\alpha$ is above 0.6 . The reliability test of the questionnaire data as follows, the results are listed in table 2. 
Table 2. Cronbach's Alpha Test

Cronbach's Alpha

898

Number of Items

The internal consistency was studied by SPSS 19.0 and the Alpha model was used. The Cronbach's Alpha coefficient is 0.898 , it indicates that the data showed good reliability.

The Average Variance Extraction (AVE) was used as the index of aggregation validity. Through testing the coefficients of the model, the values of AVE are basically meet the requirements. Overall, the aggregation validity of structural model gets comparatively ideal. The relation of variables is roughly corresponded to the urban public service satisfaction model assumption. The evaluation index in the questionnaire can effectively reflect the satisfaction of the interviewees.

\subsection{The Significance of Path Coefficient}

The model evaluation should investigate whether the estimated parameters are statistically significant, and path coefficients are tested for significance. The results obtained by AMOS.21 are shown in Table 3.

Table 3. Coefficient Estimation Result

\begin{tabular}{|c|c|c|c|c|c|c|}
\hline $\begin{array}{c}\text { Satisfaction } \\
\text { Evaluation Path }\end{array}$ & & & Estimate & S.E. & C.R. & $\mathrm{P}$ \\
\hline Quality Perception & $<--$ & $\begin{array}{c}\text { Public } \\
\text { Expectation }\end{array}$ & .318 & .024 & 13.444 & $* * *$ \\
\hline Public Satisfaction & $<---$ & $\begin{array}{c}\text { Quality } \\
\text { Perception }\end{array}$ & .827 & .071 & 11.592 & $* * *$ \\
\hline Public Satisfaction & $<---$ & $\begin{array}{c}\text { Public } \\
\text { Expectation }\end{array}$ & .104 & .033 & 3.112 & .002 \\
\hline Public Complaint & $<---$ & $\begin{array}{c}\text { Public } \\
\text { Satisfaction }\end{array}$ & .249 & .023 & 10.701 & $* * *$ \\
\hline City Image & $<---$ & $\begin{array}{c}\text { Public } \\
\text { Satisfaction }\end{array}$ & .092 & .016 & 5.847 & $* * *$ \\
\hline City Image & $<---$ & Public Complaint & .506 & .049 & 10.398 & $* * *$ \\
\hline
\end{tabular}

As can be seen from the path coefficients, there is no much nonsense variance or negative variance. So, the result is valid. As the same time, it can be seen from the significance probability value that all the parameters have reached a significant level, which indicates that the estimate of the path coefficients has reached a significant level. The path analysis of satisfaction evaluation results is shown in Fig. 3.

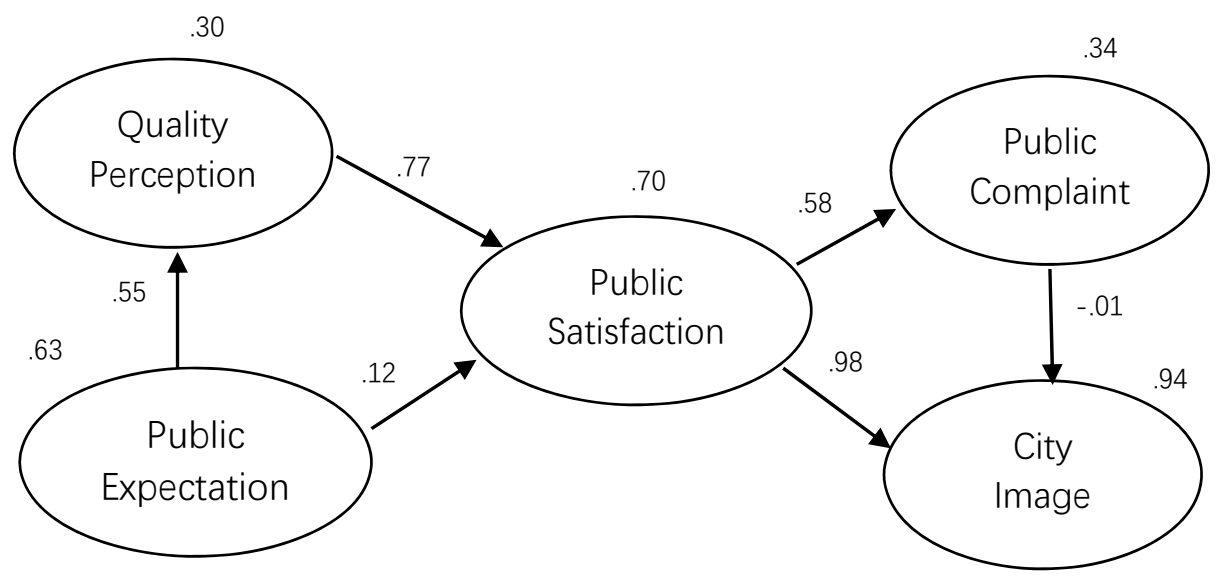

Fig. 3. Latent Variable Model of Urban Public Service Satisfaction of Changchun

We can see from Fig. 3: (1) Public Expectation has less effect on Public Satisfaction, influence coefficient is 0.12 . It shows that the service provided by government and relevant departments of Changchun has not yet reached the standard of public expectations, the public expectation is high and many high expectations out of reality are appeared. (2) Quality Perception has a significant positive affect towards Public Satisfaction, the influence coefficient is 0.77 . It shows that the public can be 
satisfied only by providing high-quality service. (3) Public Satisfaction has a strong positive affect towards City Image, influence coefficient is 0.98 . It shows that the improvement of public satisfaction is conducive to changing the image of the city. (4) There is a negative correlation between Public Complaint and City Image, influence coefficient is - 0.1 . It shows that the more public complaints the worse the city image is.

\subsection{Model Evaluation}

The model is implemented by AMOS 21. We can see from the aspect of fitting index of public satisfaction structure equation, the root mean-square error approximation (RMSEA) is 0.058 less than the minimum standard 0.08 . The value of goodness of fit index (GFI) is 0.946 larger than the standard 0.9 , the adjust goodness of fit index (AGFI) is 0.923 much larger than the standard 0.8 , the normal fit index (NFI) is 0.959 larger than the standard 0.9, the comparative fit index (CFI) is 0.969 larger than the standard 0.9. The indicators above show that the model fits well, the fitness indexes are shown in Table 4.

Table 4. Model Adaptation Index

\begin{tabular}{ccc}
\hline Evaluation Index & Index Value & Standard Value \\
\hline RMSEA: root mean-square error approximation & 0.058 & $<0.08$ \\
GFI: goodness of fit index & 0.946 & $>0.9$ \\
AGFI: adjust goodness of fit index & 0.923 & $>0.8$ \\
NFI: normal fit index & 0.959 & $>0.9$ \\
CFI: comparative fit index & 0.969 & $>0.9$ \\
\hline
\end{tabular}

\section{Recommendation}

The central government pay more attention to perfecting the urban public service system, the people's life problems are more important, the public satisfaction will have a great guiding effect on the construction of urban service and will affect the quality of urban service construction. Public satisfaction is influenced by public expectation, and quality perception of public plays an important role in public satisfaction ${ }^{[9]}$. Therefore, government departments and industries should provide high quality services, change service attitude and image, keep close to the people, and meet the expectations of public. Depending on the circumstances of Changchun urban public service, we put forward some recommendations.

Urban services should be closely related to residents' demand and coordinated development, improve the urban public infrastructure, provide high quality products and services, satisfy the resident multilevel demand and provide public services that meet their expectations.

Establish the innovation mechanism and promote the balance and coordinated development of urban public service system. Improve the mechanism of the "government-led and communityparticipated", driven by the participation of public, with the principle of public opinions, to benefit and realize their own development in the process of accept and participated in the urban public service.

Improve the efficiency of government and related departments, change the service attitude, and keep close to the people, to improve the image of the urban public service, only the service which public recognized and trusted is the good service. The higher level of public satisfaction, the less complains, the higher degree satisfaction is.

\section{Acknowledgment}

The research was supported by the Social Science Foundation of Jilin Province (No. 2016B358); the Project of Jilin Provincial Education Department (No. 2015358).

\section{References.}

[1] Fornell, C. A. National Customer Satisfaction Barometer. The Swedish Experience [J]. Journal of Marketing, 1992, 56(1): 6-20. 
[2] Anderson E. W., Fornell C., Lehmann D .R..Customer satisfaction, market share and profitability : findings from Sweden [J]. Journal of Marketing, 1994(59) : 53-66.

[3] Liu Wu. Measuring Users' Satisfaction for Governmental Public Services [J], Journal of Northeastern University (Social Science), 2006.02:129-132.

[4] Yang Fenghua. The Application of the Structural Equation Model in Public Satisfaction Evaluation of Public Secotrs [J], Journal of Nantong University (Social Sciences Edition), 2008, 05:127-131.

[5] Zhang Huiping, Yan Zefeng. Investigation on the Satisfaction of Urban Public Service-Taking Yinchuan city, Ningxia hui autonomous region as example[J], Public Finance Research,2011,09:54-57.

[6] Ji Jiangming, Hu Wei. Evaluation on Entropy Weighted TOPISIS Index of Urban Public Service Satisfaction in China: An Empirical Study Based on Lien Survey of Public Service in Chinese Cities in 2012[J], Journal of Shanghai Jiaotong University (Philosophy and Social Sciences), 2013.03:41-54.

[7] Zheng Fanghui, Wu Yi. Public satisfaction survey in local government performance evaluation [J], Marketing Research, 2007, 03:25-29.

[8] Yi Danhui. Structural Equation Models: Methods and Applications [M], Beijing: China Reming publication House, 2008.

[9] Liang Changyong, Zhu Long, Leng Yajun. The Application of the Structural Equation Model in Public Satisfaction Evaluation of Government [J], Chinese Journal of Management Science, 2012, S1:108-113.

\section{Appendix}

\section{Urban Public Service Evaluation Survey Questionnaire of Changchun}

Dear, friends:

We are conducting a survey of public service evaluation in Changchun. Your opinions will play an important role in the improvement of urban services in Changchun. Please fill in the following questionnaire. Thank you!

To ensure the authenticity of the questionnaire information, please fill the following basic information (with " $\sqrt{ }$ "), so we can sample the questionnaire and verify it:

Part I: Basic Personal Information

Your gender: $\square$ Male $\quad \square$ Female $\quad$ Your age: $\square 16 \sim 35 \quad \square 36 \sim 55$ aabove56

You are: $\square$ citizens $\quad$ working in non-city personnel in the city domicile $\square$ non-natives come

Your career: $\square$ party and government organs $\square$ public enterprise unit aarmed policemen 口enterprise staff $\square$ technology professionals arural migrants alaid-off and jobless people $\square$ retirees $\square$ students $\square$ other (please indicate___ )

We guarantee that your personal information will be used only in this urban public services and not leaked or improperly used.

Part II:Public Satisfaction Survey

Q1: What's your general expectation of public service in Changchun?

1.Very high 2.High 3.General 4. Low 5. Very low

Q2:What's your expectation of the government's commitment to "Practical Engineering"?

1.Very high 2.High 3.General 4. Low 5. Very low

Q3:What's your reliability expectations for public service in Changchun?

1.Very high 2.High 3.General 4. Low 5. Very low

Q4:Are you satisfied with the public cultural services provided by the city Changchun?

1.Very Satisfied 2.Satisfied 3. General 4. Dissatisfied 5.Very dissatisfied

Q5:Are you satisfied with the government's ability to deal with natural disasters, disease transmission 
and food poisoning?

1.Very Satisfied 2.Satisfied 3. General 4. Dissatisfied 5.Very dissatisfied Q6:Are you satisfied with the community health service centers(station)?

1.Very Satisfied 2.Satisfied 3. General 4. Dissatisfied 5.Very dissatisfied

Q7:Is it convenient for you to travel by bus in Changchun?

1.Very Satisfied 2.Satisfied 3. General 4. Dissatisfied 5.Very dissatisfied

Q8:Are you satisfied with compulsory education in Changchun?

1.Very Satisfied 2.Satisfied 3. General 4. Dissatisfied 5.Very dissatisfied

Q9:Are you satisfied with the work of anti-corruption?

1.Very Satisfied 2.Satisfied 3. General 4. Dissatisfied 5.Very dissatisfied

Q10:Are you satisfied with the overall service level of the municipal government and the relevant departments of Changchun?

1.Very Satisfied 2.Satisfied 3. General 4. Dissatisfied 5.Very dissatisfied

Q11:How do you think the difference between the public service and your expectation?

1.Very Satisfied 2.Satisfied 3. General 4. Dissatisfied 5.Very dissatisfied

Q12:Are you satisfied with the work efficiency of the municipal government and the relevant departments of Changchun?

1.Very Satisfied 2.Satisfied 3. General 4. Dissatisfied 5.Very dissatisfied

Q13:Are you satisfied with the way in which the citizens are concerned about the problems and the handing and feedback of the people concerned?

1.Very Satisfied 2.Satisfied 3. General 4. Dissatisfied 5.Very dissatisfied

Q14:How many times have you advised to the government and relevant departments?
1.A lot 2.Many
3. General
4.Less 5.A few

Q15:Do you think the city public service can meet your demands?

1.Completely 2. Basic 3.Generally 4.Basically not 5.Completely not

Q16:Do you think the city's social relationship is harmonious?

1.Very harmonious 2.Harmonious 3.Generally 4.Disharmonious 5.Very disharmonious

Q17:Are you satisfied with the growth environment of minors in Changchun?

1.Very Satisfied 2.Satisfied 3. General 4. Dissatisfied 5.Very dissatisfied Q18:Are you satisfied with the city environment?
1.Very Satisfied
2.Satisfied
3. General
4. Dissatisfied
5. Very dissatisfied 